\title{
Validated CMS: Towards New Generation of Web Content Management Systems on Web 2.0
}

\author{
Zakaria Itahriouan \\ Faculty of Sciences, Abdelmalek Essaadi University, Tetuan, Morocco \\ zakariaitahriouan@gmail.com \\ Anouar Abtoy \\ Faculty of Sciences, Abdelmalek Essaadi University, Tetuan, Morocco \\ anouar.abtoy@gmail.com \\ Kamal Eddine El Kadiri \\ Faculty of Sciences, Abdelmalek Essaadi University, Tetuan, Morocco \\ elkadiri@uae.ma \\ Noura Aknin \\ Faculty of Sciences, Abdelmalek Essaadi University, Tetuan, Morocco \\ aknin_noura@yahoo.fr
}

\begin{abstract}
Web 2.0 makes users the main actors for publishing content and creating applications on the web. The increasing of information overload and consequently the decrease of its quality are the main problems of this domain. Content Management Systems (CMS) provide the ability to publish on the web by offering simple publishing tools for ordinary users with no technical skills. Content available on the web created using the CMS is not well controlled and requires efficient process that evaluates its quality. Therefore, Content Management Systems contribute to the problem related to information and content quality similarly to Web 2.0 tools. The mechanis m of validating content has proved a high-level of content's quality control by involving users in the process according to Web 2.0 philosophy. From these perspectives, we develop Validated Content Management System (VCMS) as a new Web 2.0 tool that supports content validation mechanisms. This article presents the VCMS and its ability to provide an effective quality control for web content. We introduce a new manner of collaborative publishing and we give an overview about features of our system and its core architecture.
\end{abstract}

Index Terms - Web 2.0, Content Management System, Content Quality, Social Aspect

\section{Introduction}

The main actors of web 2.0 are internet users. These way users become co-creators of new online applications, often initiating collectively or in community a new form of digital relations ${ }^{[1]}$. The concept of Web 2.0 introduced by Tim O'Reilly in 2004 was finally summarized in October $2005^{[2]}$ under seven key principles:

- Web as a Platform.

- Harnessing Collective Intelligence.

- Data as the next Intel Inside.

- End of software release cycle: the "perpetual beta".

- Lightweight Programming Models.

- Software above the Level of a Single Device.

- Rich userexperience.

The user would then become at the same time consumer and actor that produce, publish, distribute, index and share content of all types. The following figure shows a comparis on between the classical Web (Web 1.0) and the second generation of the Web (Web 2.0) according to several viewing angles.

Table 1: from Web 1.0 to Web $2.0^{[3]}$

\begin{tabular}{|l|l|l|}
\cline { 2 - 3 } \multicolumn{1}{c|}{} & \multicolumn{1}{c|}{ Web 1.0 } & \multicolumn{1}{c|}{ Web 2.0 } \\
\hline Web Leaders & Businesses, merchants & Internet users \\
\hline User Profile & Passive & Active \\
\hline $\begin{array}{l}\text { Percei ved } \\
\text { interactivity }\end{array}$ & $\begin{array}{l}\text { Selecting and reading } \\
\text { information }\end{array}$ & $\begin{array}{l}\text { Selecting, reading } \\
\text { and data } \\
\text { publishing }\end{array}$ \\
\hline Research Unit & Keyword & Tag \\
\hline
\end{tabular}

Web 2.0 is not an evolution of concept or technological dimensions, its applications are based on 
existing technologies. Web 2.0 uses mainly the following tools:

Table 2: Web 2.0 tools $^{[4]}$

\begin{tabular}{|l|l|}
\hline \multicolumn{1}{|c|}{ tools } & \multicolumn{1}{c|}{ Utility } \\
\hline Blog & Publishing and sharing content \\
\hline Wiki & Collective Intelligence \\
\hline Social Net works & Online Communities \\
\hline RSS & Content Syndication \\
\hline Tag & Improving research \\
\hline Podcast and Videocast & Sharing multimedia content \\
\hline
\end{tabular}

While Web 2.0 has created an evolution in philosophy of the web by making easy publishing, we have many limitations resulting ${ }^{[5]}$. Some limitations refer to users:

- A limited number of participants.

- Low turnout.

- Heterogeneous participants

- Motivation of participants.

- Some limitations refer to produced information:

- Low quality of information.

- Expanding the amount of information.

- Lack of security and copyright.

- Lack of semantics.

Content management Systems have an important role in expanding publishing amount where improving it in adding new modules for content evaluation become a necessity. In order to overcome these limitations we propose in this paper the architecture of a new Web 2.0 tool as a Content Management System, enabling web content's classification and user's management based on philosophy of content validation.

The rest of this paper is organized as follows: In Section 2 we give features of Web Content Management Systems and its architecture. In Section 3, we introduce content validation theory. Section 4 is developing the CMS toward a validated system based on user's contribution and maintaining social relationships in collaborating to finally publish high quality content. In Section 5, we conclude and present future prospects of this work.

\section{Web Content Management Systems:}

Web Content Management Systems allow users with little or no web design or programming experience to create and update content on the Web. Some of these systems provide a What You See Is What You Get (W YSIW YG) editor for the content. They offer a level of security for granting access to update or delete content. Content Management Systems may offer to users a workflow to manage entry, approval, and publishing steps so that a user can enter new content. However, another service is required to approve and publish that content using another level of security. Content often has a date of publication, sometimes with an expiration date, and can be reusable on other pages of the site ${ }^{[6]}$.

Content Management Systems are widely used to create content on the Web. Many of these systems offer possibility to publish content classified as Web 2.0 content.

\subsection{CMS Features:}

We can look at a CMS as a publishing tool that allows users to create, edit, delete, and present content in various forms including text, imagery, video, sound, and animation. But there's much more to a CMS than this. A better way to come up with a definition of CMS technology is by pointing to a set of features that are as sociated with CMS technology ${ }^{[7]}$ :

- Allow users to easily search for information using well-defined categories.

- Present content to users quickly.

- Offer users the choice of different presentation views.

- Offer users the choice of different content views.

- Allow administrators of the CMS to monitor and manage content and users.

- Allow authors to manipulate content.

- Provide facilities that allow users to communicate with others in a forum format.

- Provide an open architecture to support pluggable components.

- Allow for future expansion of metadata.

\subsection{CMS Architecture:}

The current Content Management Systems have many different frameworks, many different types of data storage, many different platforms, and many different languages available to meet the needs for building a sturdy CMS. By allowing a CMS to piggyback with Web server technology, presentation and delivery of content is simplified because file formats already exist and middle-ware technology is already in place that allows for the manipulation and integration and dynamic delivery of content to the end user. Furthermore, because middle-ware is already in place, accessing other types of server technology (such as databases) is simplified, in comparison to having to write supporting software to tie different servers and server types together.

The architecture of a CMS is principally based on tiers, where a tier is a distinct and independent component that offers a specific service within a greater system of running software. Tiers usually run on separate computers and communicate with each other using various protocols ${ }^{[7]}$.

The most advanced architecture of CMS is the based five-tiers as we see on Fig. 1: 


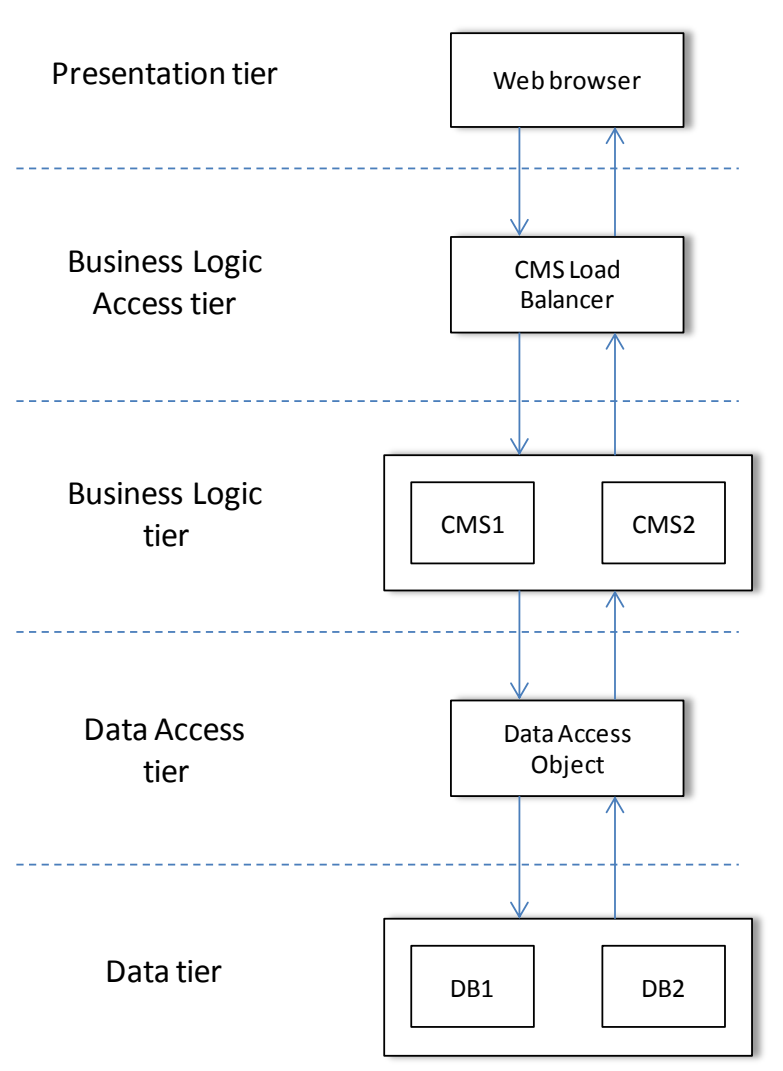

Fig. 1: Five-tiered CMS architecture ${ }^{[7]}$

\section{Content Validation:}

Production of content on the Web was not subject to any control of quality and relevance. The approach proposed by our team ${ }^{[8]}$ introduced a validation model that supports monitoring the quality of content along its life on the Web. It focuses on prioritizing information and users both:

- Information: content is classified into categories that represent a range of quality, this organization facilitates the classification of content according to relevance of information.

- Internet users: users are classified into groups with certain privileges and responsibilities. We have: producers (producing content), validators (content validation and approving) and experts (supervision of validation).

Produced content passes through two processes:

- Static validation: conducted by the validation committee (experts and validators). This operation is to evaluate the quality of content by two validators and one expert. If the quality is not satisfactory, content will be rejected. Otherwise, it will be published with an initial quality (fig.2).

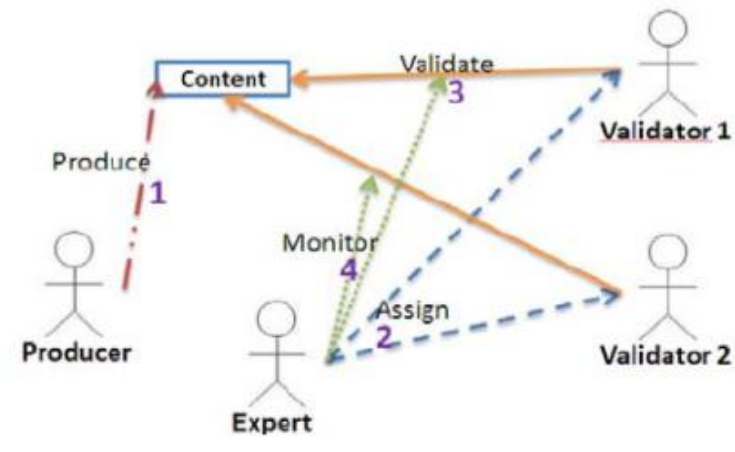

Fig. 2: Static validation ${ }^{[8]}$

- Dynamic validation: This part is performed by users themselves. Every user has the right to evaluate the content with a note that reflects its quality. The lifetime of the latter is controlled by his note which varies dynamically (fig.3).

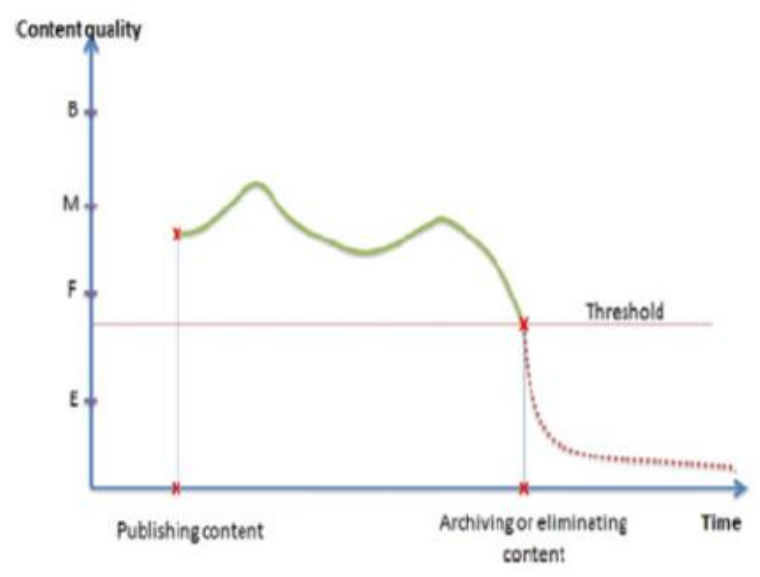

Fig. 3: Dynamic validation ${ }^{[8]}$

\section{Validated Content Management System}

We have seen that CMS provide the ability to publish on the Web while making easy publishing with no need to have experience in developing web pages. Content available on the web created using the CMS is not well controlled and lacks of efficient process that evaluates its quality. The mechanis $m$ for validating content revealed a high-level of quality control for content while putting users as main actors according to Web 2.0 concepts. In this part we explain how we develop the CMS toward a validated system based on user's contribution and maintaining social relationships in collaborating to finally publish high quality content.

\subsection{From CMS into VCMS}

VCMS is simply a CMS that supports the structure of Content Validation and bringing more features. We will not build a new system, but making improvements to the architecture of CMS based on the following concepts: 


\subsubsection{Quality Control:}

The workflow of CMS has an automated mechanis $\mathrm{m}$. The author selects a template and a sequence of approvers to approve his content then the automatic workflow does the rest of the work. It ensures that the content does not get published to the website until and unless the sequence of editors and approvers approve it via the automated workflow ${ }^{[9]}$.
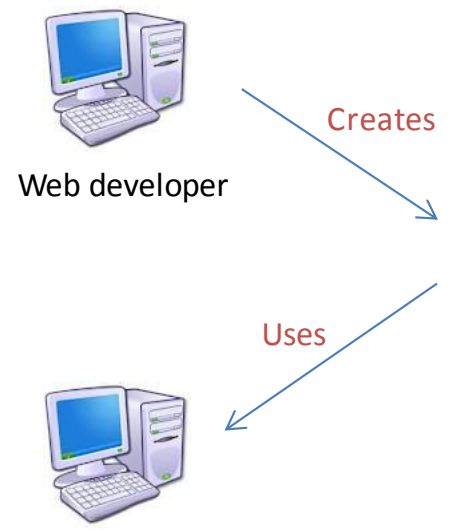

Content Author

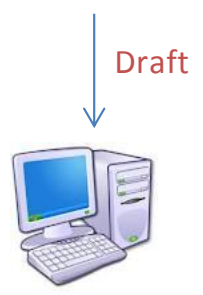

Content Manager

Approval

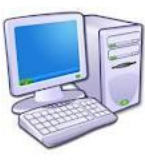

Approver

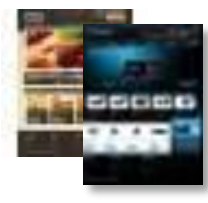

Templates
Fig. 4: automated workflow provided by CMS

In the VCMS content can be published only after passing through the process of static validation and will be controlled along its life by dynamic validation according to the following diagram:

A centralized database of VCMS's users where these last are classified by role (expert, validator, producer, and visitor) and do mains of experience allows for better evaluation of the content.

Any content that passes through the static validation is considered a project for all concerned users. Access rights to this project vary according to its state and the role of each user. The following table explains the different states of a project created by the VCMS well as the rights of each user based on project status:

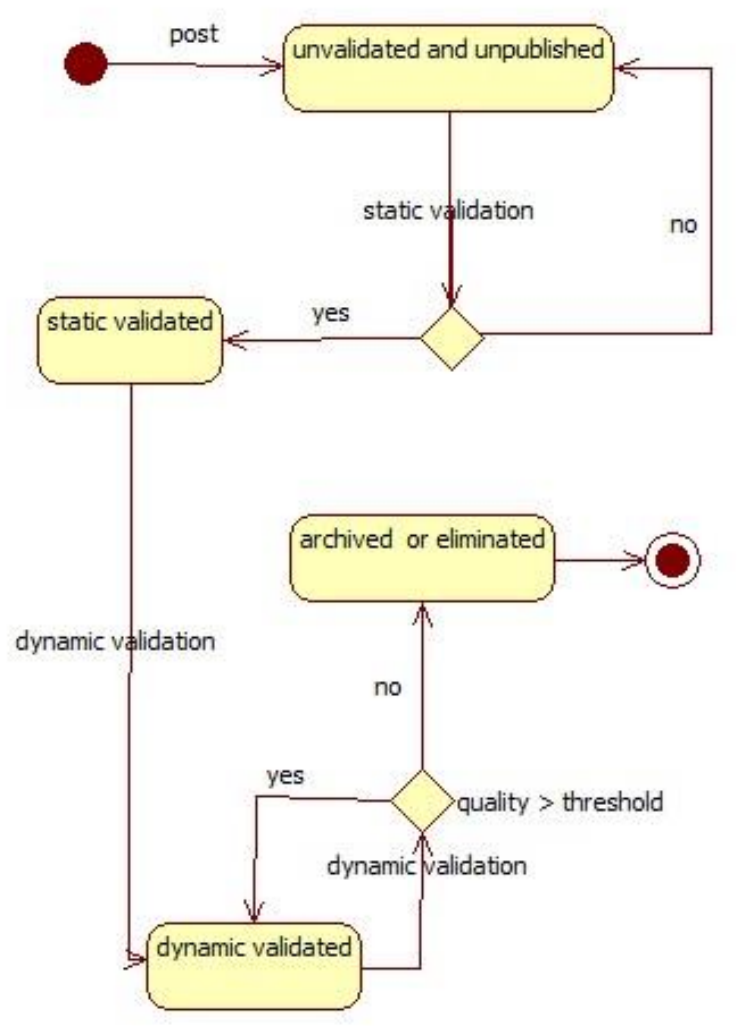

Fig.5: Content lifecycle ${ }^{[8]}$

Table. 3 user's rights depending on project status

\begin{tabular}{|l|c|c|c|c|}
\hline $\begin{array}{l}\text { Project } \\
\text { status }\end{array}$ & producer & validator & expert & visitor \\
\hline $\begin{array}{l}\text { Before } \\
\text { validation }\end{array}$ & all & none & none & none \\
\hline $\begin{array}{l}\text { Under } \\
\text { validation }\end{array}$ & Modify & all & read & none \\
\hline Validated & read & read & read & read \\
\hline $\begin{array}{l}\text { Under } \\
\text { update }\end{array}$ & modify & modify & read & none \\
\hline
\end{tabular}

The producer of the content cannot modify his content after its validation, he must request once again for the update. The same users that were selected for validation have to control this update.

\subsubsection{Real Time Collaboration:}

Content validation process requires collaborative work between the producer and the validator when the content is being static validated. The validator can correct, make changes and help improve the quality of content at its validation.

Content is not always built by a single user, the project created by the VCMS may be joint among several producers who must work on the same project. Our system allows another workflow to producers in addition to validation's workflow. A major producer can share working on his project with other users. 
The implementation of this real-time collaboration can facilitate collaborative work and also the productivity of this system keeping mechanisms enabling quality control.

\subsubsection{Social Aspect and Credibility:}

Content validation in VCMS is based mainly on internet surfer's implication. The validated content approach divides users into categories with certain duties and privileges. In order to have an idea about internet user's skills or domain of expertise we need to ensure a unique and credible identity over the web. The credibility and the identity of users is a major concern for the web [10][11][12], and particularly for content production and authorship on the web $2.0^{[13]}$. From this perspective rises the necessity to adapt the concept of author or user's credibility to web 2.0 environment and particularly in our VCMS. The new credibility can be founded on four princip les ${ }^{[14]}$ : Bio metrics usage, Usercentric system, the uniqueness of online identity and its interoperability.

According to the Nielsen Company, users spend more than five and half hours on social networking sites ${ }^{[15]}$. From this perspective, social and professional networks, forum and groups are the excellent place to gather information about the user domain of expertise and interests (Fig. 6). The establishment of an obligatory profile which contains information about users from these different resources allows avoiding their anonymity and relation's reinforcing between users. This information will be used later to make the decision in the assignment of validators to certain content based on their domain of expertise.

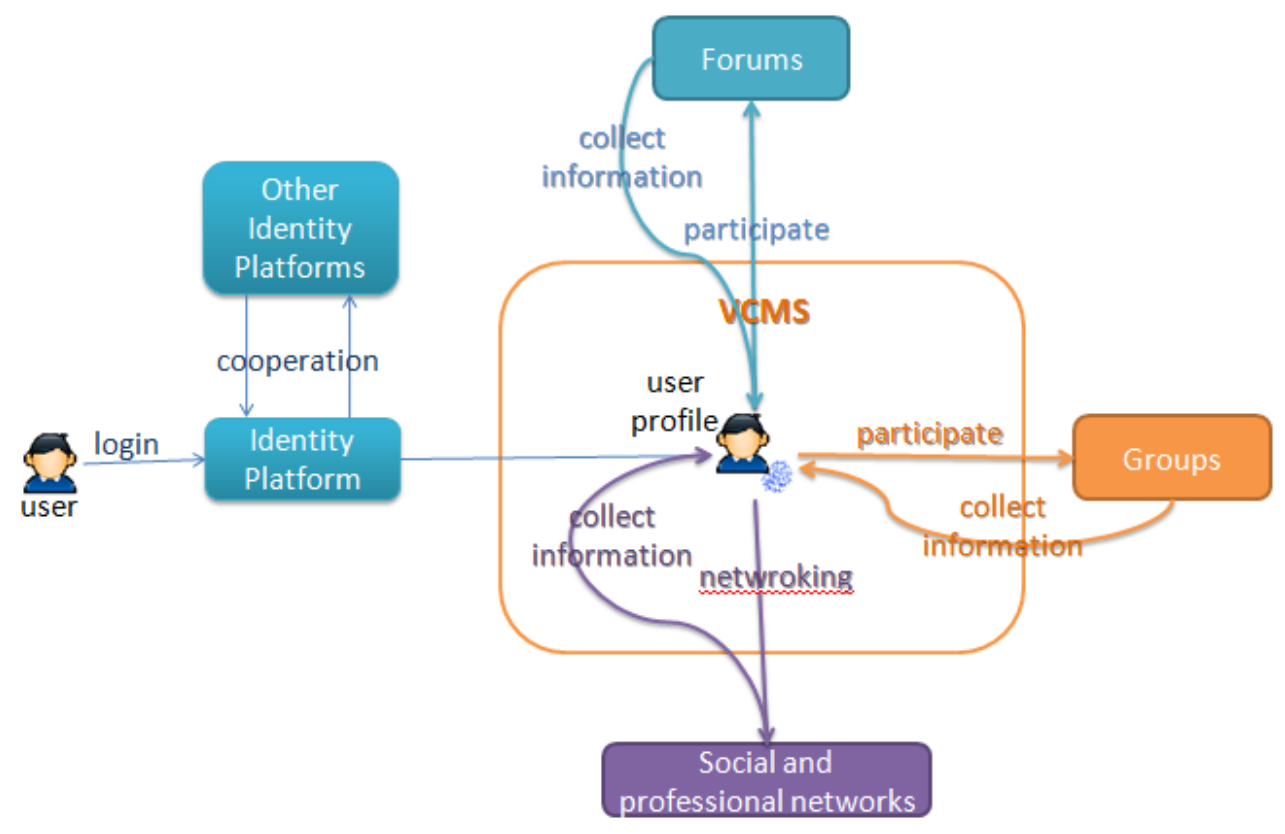

Fig. 6: User profile and the web applications activity interactions

\subsection{VCMS Architecture:}

In this part we present the design of VCMS detailing the different units and processes.

\subsubsection{User Interface:}

This interface must present to user a set of tools on the browser in HTML format allowing him to handle the system according to his rights. Functionalities of the interface presented on the browser differ from one user to another. An authentication procedure indicates the role of user in the hierarchy of the VCMS Workflow and determines its rights in all related projects. Authentication can be done in two ways by fingerprint or by usual method ${ }^{[8]}$.

The following figure shows the architecture of this interface based on three main kinds of tools:

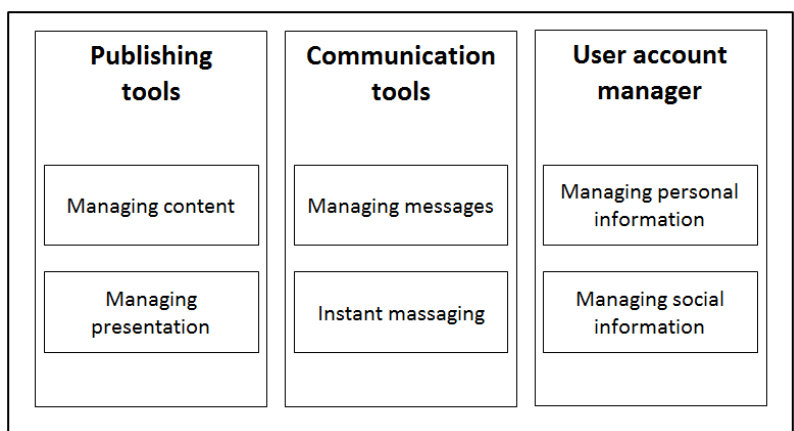

Fig.7: VCMS user interface architecture

a. Publishing Tools:

- Allows the user to manage content (create, modify, update ...) and facilitate the integration of any type of content (text, image, video ...). The VCMS user doesn't manage only the content, for 
example a validator can have both work for publication and maybe others to validate. Publishing tools must be able to manage all this work by presenting them as a projects; each project is independent of the other.

- Present the predefined template in the VCMS, allow adding new templates and facilitate the management of content presentation.

\section{b. Communication Tools:}

- Allows to manage sending, messaging, archiving, and must also submit the priority of certain administrative messages. Users are identified by the ID used in their profile.

- Allows instant communication and manipulation of conversations in real-time. Communications may also be in voice or video extension. This tool should present the list of contacts and allow its management to user.

\section{c. User account manager:}

- Allows presenting all information about the user himself and other users depending of advanced security options. Access rights to user's information change the presentation according to the role of consultant user.

- Allows the extraction of different information about users from their profiles in social networks in accordance with the security measures of these lasts. It can also present some of their information from these networks on the profiles of users in the VCMS.

\subsubsection{System Architecture:}

In this part we develop the set of processes that will manage our VCMS. We will divide this layer to a set of components or processing units such that some components are conventional and exists in the majority of Content Management Systems (data model loader, look and feel manager, content query process), and others are specific to our VCMS (validation process, User account manager, messaging manager).

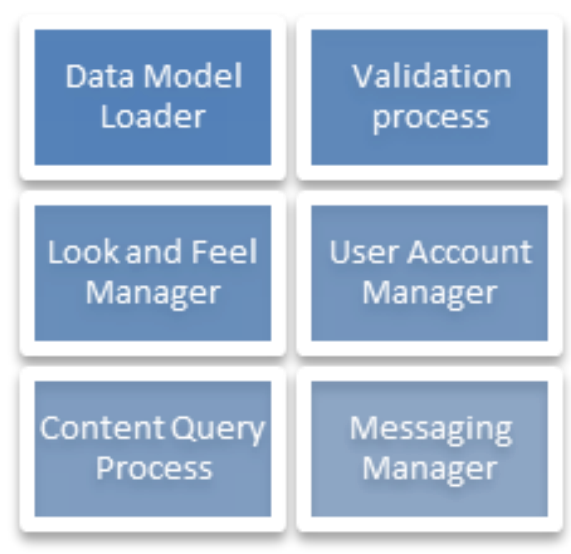

Fig.8: VCMS system's architecture

\section{a. Data model loader:}

Have to load all types of data into tables in database. It should read the source data files, convert them to different formats and finally insert the data converted into the database. The following diagram shows the process for loading data:

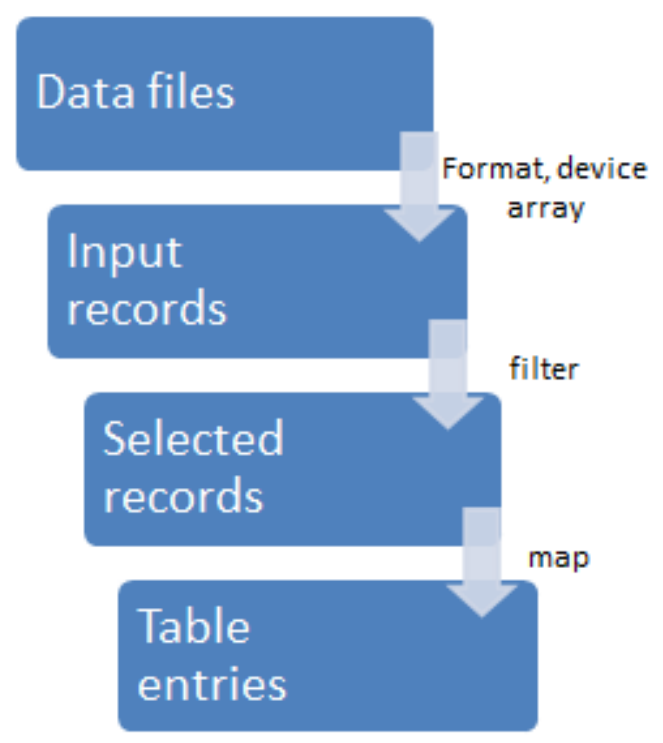

Fig.9: Data-load process

\section{b. Look and feel manager:}

Have to manage all the processes available on the design interface, allows them to customize without using the style code and automatically generate it. The processes of this unit are available to publisher of content at its inception or update, the validator can handle this unit just during validation. The change in page's style should apply to all content published immediately when changing the template. This technique uses the XSLT transformation defined in the XML standard ${ }^{[16]}$.

VCMS requires collaborative work between users especially between producers and validators. The ideal manner for collaboration is that both users contribute in the same project. The look-and-feel manager should manage this new concept and bring more rapidity to present changes made by a user to the other collaborators.

Implementation of real-time collaboration is to support modifications made by users on the display interfaces for all users. Source code is always the basis of created content. Changing the source code generated automatically by the VCMS causes the change in presentation for all users. The following figure explains this concept: 


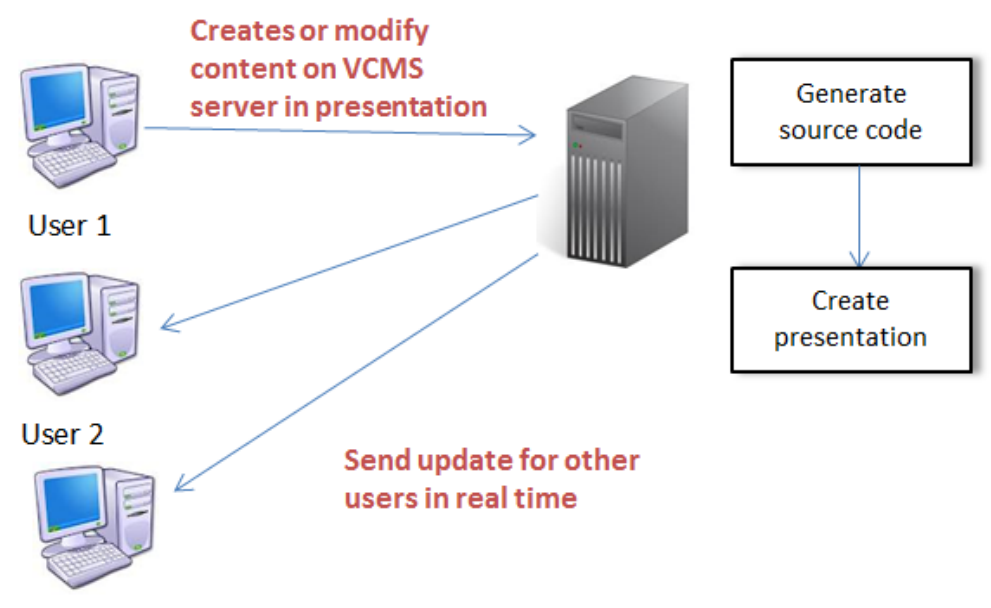

User 3

Fig.10: VCMS real time update

\section{c. Content Query Process:}

Have to respond to all queries from all users in the content published. This unit has to query processing due to the given set of options in the customization of researches. VCMS should offer the possibility to find the appropriate content in time. Search options are displayed depending on the type of content published using the VCMS. This unit should display all possible search results and according to several presentations.

\section{d. Validation Process:}

This is the core of our system that has to automate the whole process of validation ${ }^{[17]}$. The following diagram explains the procedure for creating a validation's project to be launched after the step of content's creation, which is an example of processes managed by this unit:

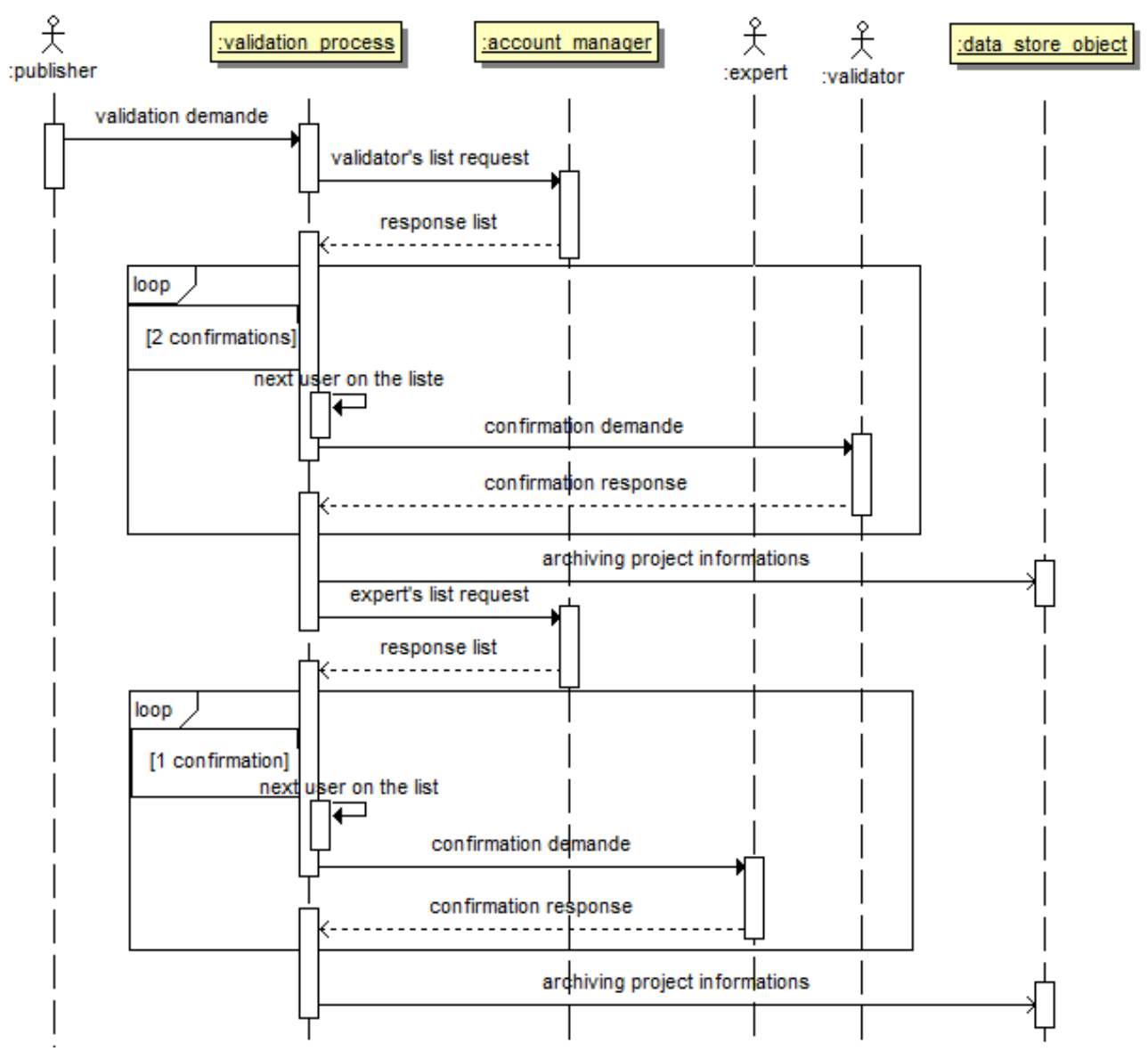

Fig.11: validation project creation 


\section{e. User Account Manager}

Have to manage user accounts and classify them in specified categories for users in our system, this unit must automatically run the passing mechanism between the roles. Each user has a profile that contains user's tags given by user himself to clarify its areas of competence. Other tags are automatically added in functions of its participation (published content) and also from its social profile to identify the area of expertise of the user.

The process of production and content's validation calls to several Internet user profiles according to the theory of content validated. The transition from a simple producer to a validator and then an expert requested the following procedures:

\section{- User-validator process :}

Each Internet user has an activity factor that accounts for its participation in the VCMS. This factor is based on the number of published content and the average of their grades (quality). When an activity factor of a user reaches a certain level (predefined by the validation committee), two validators automatically receive a suggestion to change the role of the latter toward a validator. The two validators with Tags more appropriate with those of the user will be assigned automatically by the system to upgrade it (Fig.12).

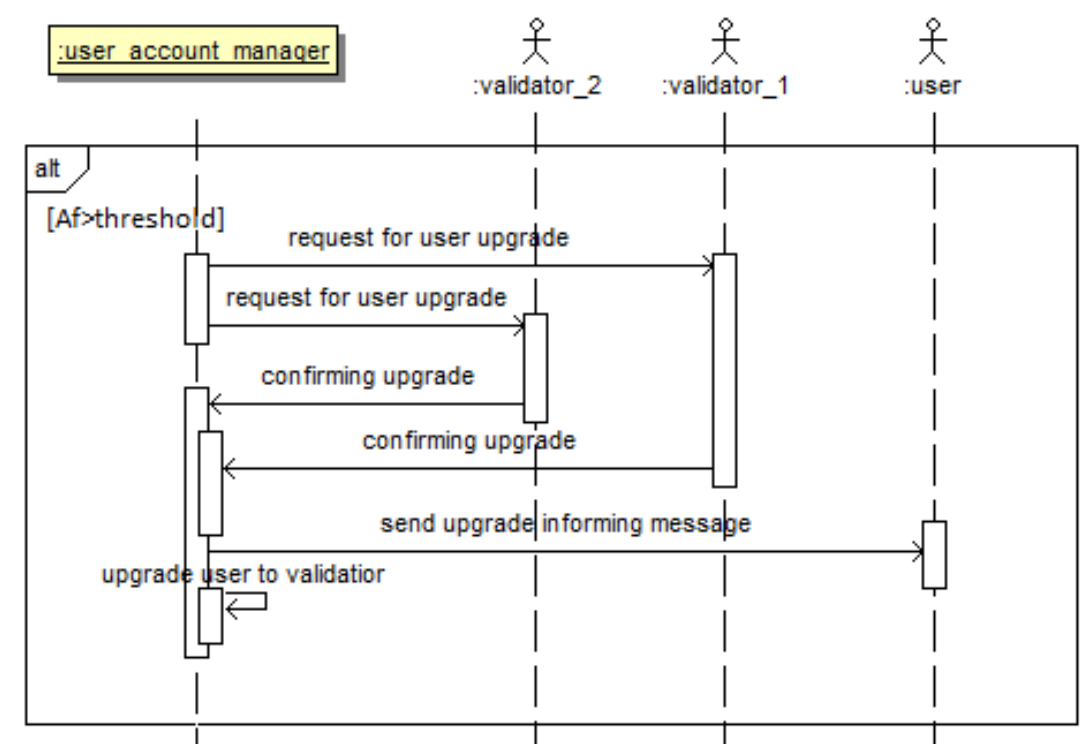

Fig.12: User-validator process

- validator-expert process:

In analogy to the user (producer) each validator has a validation factor based on the number of validated content and the average of their grades. When the validation factor of a validator reaches certain level, two experts receive an automatic suggestion to upgrade the role of the latter to an expert. The choice of two experts in the system is based on their tags in order to have a maximu matching in the field of expertise (Fig.13).

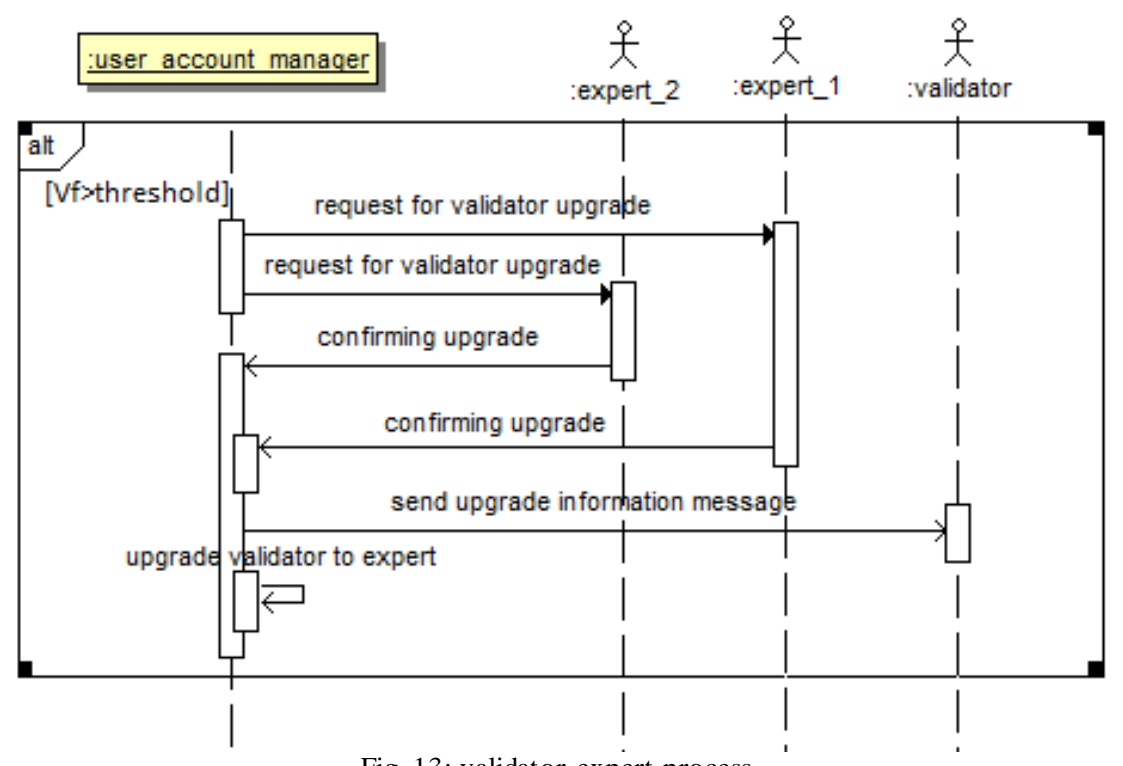

Fig. 13: validator-expert process 


\section{f. Messaging manager:}

In this part we explain the architecture of the unit that manages messaging in our system. This unit should provide instant communication between users. In our system we use an external instant messaging server that supports the following architecture:

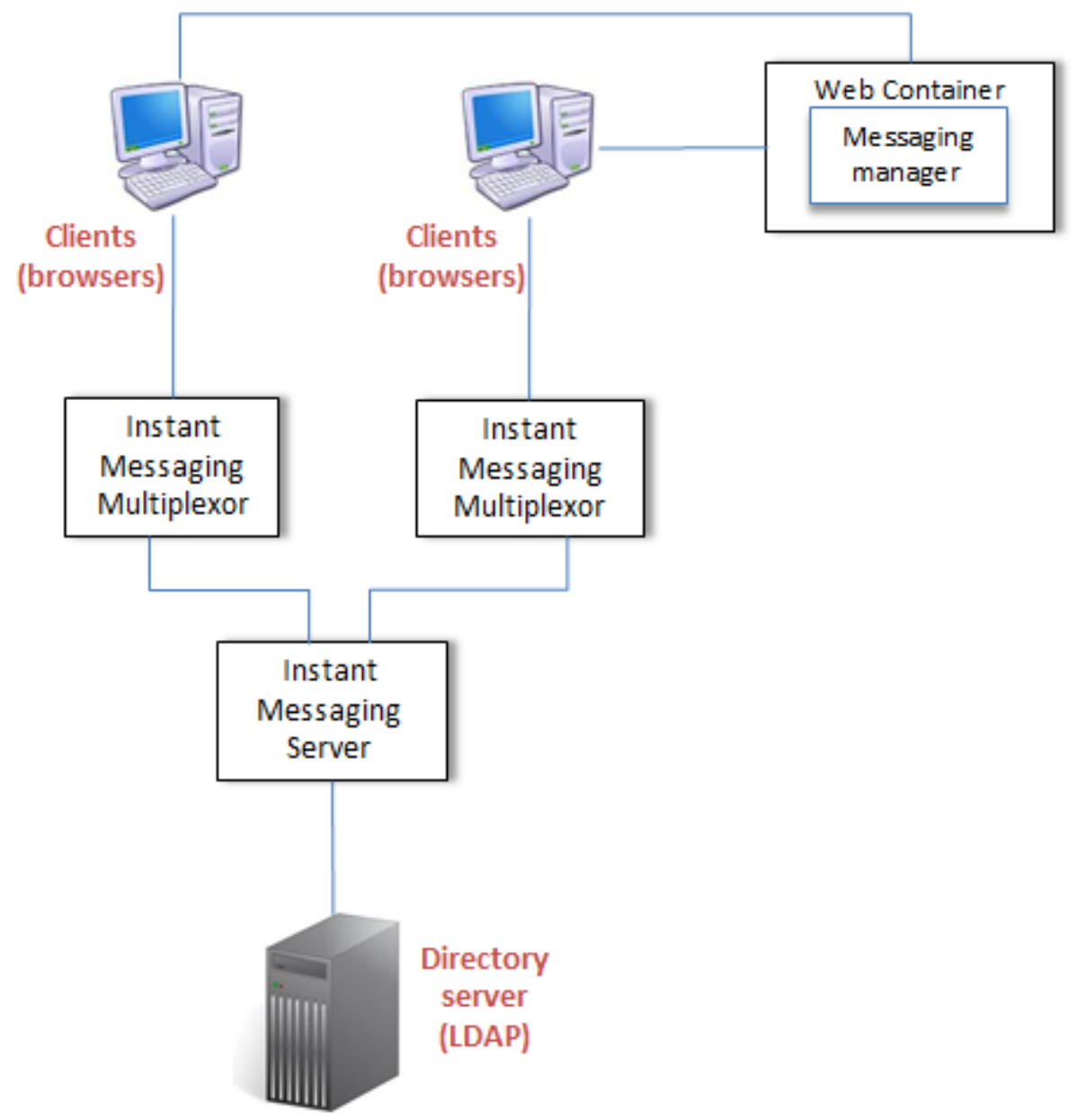

Fig. 14: Instant messaging architecture

- The LDAP server provides user entries for authentication and research.

- Users load resources instant messaging from the database of VCMS.

- Clients always connect to mail server through the instant mess aging multiplexer.

\section{Conclusion}

Validated Content Management System we build uses the mechanis $m$ of content validation and offers more features improving these systems and building a new generation of Content Management Systems. This system ensures the relevance of the content posted by its users with a solid workflow based on the participation of Internet users actively. We finally build a set of tools that allow solving some limitations of Web 2.0 respecting its principles. As prospects of this work we will extend our system to be applied to online learning systems which are one of our research fields that need high quality content and organized workflow.

\section{References}

[1] H. Guillaud, "Qu'est-ce que le web 2.0", Internet Actu, $29 \quad$ mai 2005 http://www.internetactu.net/?p=6144 accessed 5 April 2012

[2] T. O'Reilly, "What is Web 2.0" http://www.oreillynet.com/pub/a/oreilly/tim/news/ 2005/09/30/what-is-web-20.html accessed 5 April 2012

[3] F. bordage, "Comment se construit le web 2.0", ZDNet France, 29 Mars 2006 http://www.zdnet.fr/actualites/internet/0,39020774, 39334479,00.htm accessed 8 April 2012

[4] J.F Gervais, "Web 2.0 : les internautes au pouvoir", Edition Dunod, 2007

[5] A. Abtoy, N. Aknin, B. Sbihi, A. El Moussaoui and K.E. El Kadiri, "Towards a Framework for a validated content management on the collaborative Web: Blogs case", IJCSI International Journal of 
Computer Science Issues, Vol. 8, Issue 3, No. 2, May 2011, pp. 96-104.

[6] C. Christianson and J. Cochran "ASP.NET 3.5 Content Management System Development", PACKT Publishing, June 2009

[7] A. Ferguson "Creating content management systems in java", Charles River Media Publishing, 2007

[8] A. Abtoy, N. Aknin, B. Sbihi, A. El Moussaoui and K.E. El Kadiri, "Content validation as a tool for new pertinent Web 2.0 Blogs", IJCSI International Journal of Computer Science Issues, Vol. 9, Issue 3, No 3, May 2012, pp. 146-151.

[9] G. Kathuria, "web content management with documentum”, PACKT Publishing, 2006

[10] M. Small," Business and technical motivation for identity management", Information Security Technical Report, Volume 9, Issue 1, (JanuaryMarch 2004), pages (pp. 6-21)

[11] C. Satchella, G. Shanksa, S. Howardab and J. Murphy, "Identity crisis: user perspectives on multiplicity and control in federated identity management", Behaviour \& Information Technology, Volume 30, Issue 1, (January 2011), pages (pp. $51-62$ ).

[12] T. J. Johnsona, and B; K. Kayeb, "In blog we trust? Deciphering credibility of components of the internet among politically interested internet users", Computers in Human Behavior, Volume 25, Issue 1, (January 2009), Pages (pp. 175-182)

[13] B. Dogu, Z. Ziraman and D. Emrah Ziraman, "Web Based Authorship in the Context of User Generated Content, An Analysis of a Turkish Web Site: Eksi Sozluk", 4th Global Conference on cybercultures, Austria (March 2009). Available at: http://www.inter-discip linary.net/wp-

content/uploads/2009/02/dogu-paper.pdf. accessed 17 June 2012

[14] A. Abtoy, N Aknin, B. Sbihi, A. El Moussaoui and K. E. El Kadiri, "On line identity and producer's credibility in the participatory web", Proceedings of the EuroMediterranean Scientific Congress on Engineering, Algeciras 2011.

[15] The Nielsen Company, "Led by Facebook, Twitter, Global Time Spent on Social Media Sites up 82\% Year over Year", January 22, 2010 , available at : http://blog.nielsen.com/niels enwire/global/led-byfacebook-twitter-global-time-spent-on-socialmedia-sites-up-82-year-over-year/ accessed 17 June 2012

[16] L. R. E. Quin "XSLT Transformation" http://www.w3.org/standards/xml/transformation accessed 13 July 2012
[17] Z. Itahriouan, A. Abtoy, K. E. El Kadiri, N. Aknin \& B. Sbihi, "Processus de validation dans le système de gestion du contenu validé." Proceedings of the third Mediterranean Symposium on Telecommunications, Fez Morocco, March 22, 23 \& 24, 2012

\section{Authors' Profiles}

Zakaria Itahriouan: received the Master degree in telecommunication systems engineering in 2009 from Abdelmalek Essaadi University in Tetuan, Morocco. Currently, he is a PhD Student in Computer Science in Laboratory of Computer Science, Operational Research and Applied Statistics in same university. His current research interest is Web 2.0, Distance Learning, Content Management systems and Web content quality.

Anouar Abtoy: received the PhD degree in Computer Science from Abdelmalek Essaadi University in Tetuan, Morocco. His areas of interest include Web 2.0, collaborative and collective intelligence, online identity, evaluation and assessment of information and content.

Kamal Eddine $\mathbf{E}$ Kadiri: received the "Thèse de troisième cycles" degree in Data analysis at Paris VI University in 1984. He received "Thèse d'état" degree in Computer Science from Granada in 1994. . In 2007 he received the international master in E-learning in the Curt Bosh institute in Switzerland. He is a professor of Mathematics and Computer Science at Faculty of Sciences of Tetuan in Morocco. Currently, he is the director of the National School of Applied Sciences (ENSA) of Tetuan and also the director of LIROSA laboratory. He has published several articles on Elearning and Web 2.0. He is also part of many boards of international journals and international conferences.

Noura Aknin: received the the $\mathrm{PhD}$ degree in Electrical Engineering in 1998 from Abdelmalek Essaadi University in Tetuan, Morocco. She is a Professor of Telecommunications and Computer Engineering in Abdelmalek Essaadi University since 2000. She is the Co-founder of the IEEE Morocco Section since November 2004 and she is the Women in Engineering Coordinator. She has been a me mber of the Organizing and the Scientific Committees of several symposia and conferences dealing with RF, Mobile Networks, Social Web and information technologies.

How to cite this paper: Zakaria Itahriouan, Anouar Abtoy, Kamal Eddine El Kadiri, Noura Aknin,"Validated CMS: Towards New Generation of Web Content Management Systems on Web 2.0", IJITCS, vol.4, no.12, pp.40-49, 2012. DOI: $10.5815 /$ ijitcs.2012.12.04 